\title{
Optical Fiber Nonlinearity Estimation Through Four-Wave Mixing
}

\author{
Dr. Tariq A. K. Al-Jumailly \\ Computer Eng. Dept.- College of Eng.- Mosul University- Iraq. \\ Email: dr.tariq.aljumailly@gmail.com
}

\begin{abstract}
Optical wavelength converters are very important devices in optical Dense Wavelength Division Multiplexing (DWDM) Systems. Among numerous wavelength technologies Four-Wave Mixing (FWM) in optical fibers is attractive because it offers strict transparency to amplitude, frequency and phase. They also have the ability to convert multiple wavelengths simultaneously and to invert optical spectra. Four-wave mixing conversion efficiency depends upon fiber nonlinearity.

The effects of fiber nonlinearity play a decisive role in the design and performance of modem optical communication links. So it is important to measure the nonlinear promising technique for determining fiber nonlinearity $(\gamma)$. This paper investigates a way of estimating fiber nonlinearity through four-wave mixing process.
\end{abstract}

Keywords: Optical fiber communications, Fiber measurement, computer networks.

$$
\begin{aligned}
& \text { حساب لاخطية الليف الضوئي من خلال خلط الامو اج الاربعة } \\
& \text { قسم هندسة الحاسوبـ كلية الهندسة جامعة الجميلي الهوصـ العراق } \\
& \text { الملخص: الأصنات }
\end{aligned}
$$

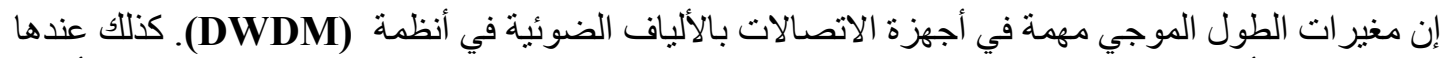

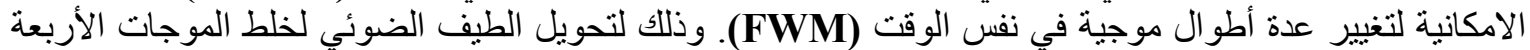

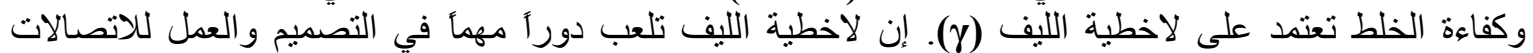

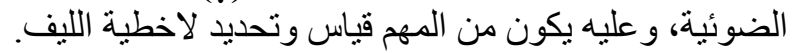

$$
\begin{aligned}
& \text { في هذا البحث تم تقديم طريقة لتقدير لاخطية الليف من خلال أربع موجات وبطريقة الخلط. }
\end{aligned}
$$




\section{Introduction}

Nonlinear effects in optical fibers such as stimulated Raman scattering (SRS), stimulated Brillion scattering (SBS) and optical Kerr effect have many useful applications in telecommunications and in optical signal processing[1], [2]. The optical Kerr effect, in which the refractive index changes with optical power, leads to various secondary effects such as self-phase modulation, cross-phase modulation, modulation instability and FourWave Mixing.

Applications using Kerr effect include optical parametric amplification, frequency conversion [3], optical phase conjugation [4], pulse compression [5] and regeneration [6]. Each of these applications requires properly designed single mode fibers with high nonlinearity, right dispersion properties and low attenuation. This nonlinear coefficient in optical fibers is determined by two factors [7]. The first one is the nonlinear refractive index $\left(\mathrm{n}_{2}\right)$ which depends on the fiber material. Optical fibers used in communications do not possess a high nonlinearity coefficient, however the nonlinear phenomena can be observed at very high intensities of light and at large transmission distances [1].

Although the power used at transmission of signals is not of very high intensity in the fiber [several tens of mWatts], the light intensity in the fiber is very high [4]. This is owing to the fact that the cross-section of the fiber is very small $10^{-7}$ or $10^{-8} \mathrm{~cm}$ for single mode fibers, so the light intensities acting upon a fiber reach as much as several $\mathrm{GW} / \mathrm{cm}$, such an intensity value is sufficient for inducing nonlinear effects, thus significantly influencing the light propagation in a fiber over different distances.

The second one is the effective area of the fiber which is related to fiber design. Nonlinear optical fibers have been used as wavelength converters through the process of four-wave mixing [8]. This paper discusses the process of fiber nonlinearity estimation through the four-wave mixing process.

\section{Four-Wave Mixing (FWM)}

Four-wave mixing in optical fibers is an effect produced by the intensity-dependent refractive index, occurs when two or more wavelengths of light propagate together through an optical fiber. Light is generated at new frequencies using optical power from the original signals. This generation of new frequencies is subjected to a condition known as phase matching [9]. Assuming that self and cross-phase modulation (SPM) and (PM) are ignored, the power of the generated wave is given by [10]

$$
P_{3}(l)=\eta \gamma^{2} P_{1} P_{2} \operatorname{EXP}(-\alpha l)\left[\frac{\left.\{1-E X P(-\alpha l)\rfloor^{2}\right]}{\alpha^{2}}\right]
$$

where $l$ is the fiber length, $\alpha$ is the fiber attenuation coefficient, $\gamma$ is the nonlinear coefficient of the fiber, and $\eta$ is the FWM efficiency for (W3). The nonlinear coefficient $\gamma$ is given by [10]:

$$
\gamma=\left\lfloor\frac{2 \pi n_{2}}{\lambda A_{e f f}}\right\rfloor
$$

where $A_{\text {eff }}$ is the effective fiber core area, $\lambda$ is the wavelength and $\mathrm{n}_{2}$ is the fiber nonlinear refractive index. The determination of fiber nonlinear coefficient can be done by using FW as shown in Fig. 1. 


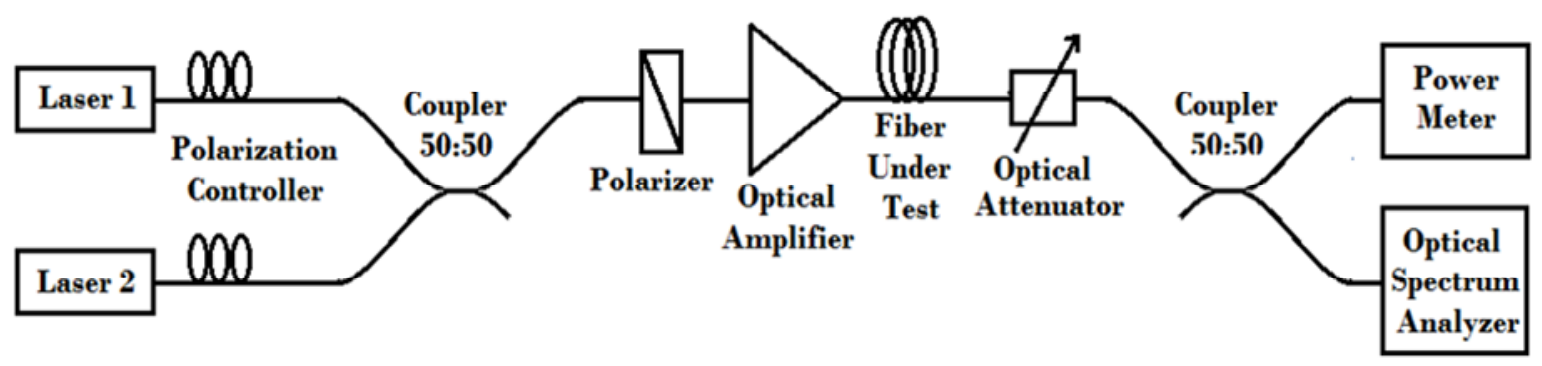

Fig. I A termination of the nonlinear fiber.

\section{Results}

As the severity of the nonlinear effects is dependent on the intensity distribution inside the fiber, it is convenient to use the nonlinear coefficient $\left\lfloor\frac{n_{2}}{A_{e f f}}\right\rfloor$ to represent the magnitude of this phenomenon. The nonlinear coefficient can be $\left[\frac{n_{2}}{A_{\text {eff }}}\right]$ determined directly from the slope of the nonlinear phase shift as a function of optical power (neglecting the effects of dispersion) as shown in Fig. 2.

The frequency behavior of wavelength converter regions is shown in Fig. 3 via determining the conversion efficiency variations with frequency. Such figure illustrates the wide-band operation of these converters, while neglecting the impact of SNDE.

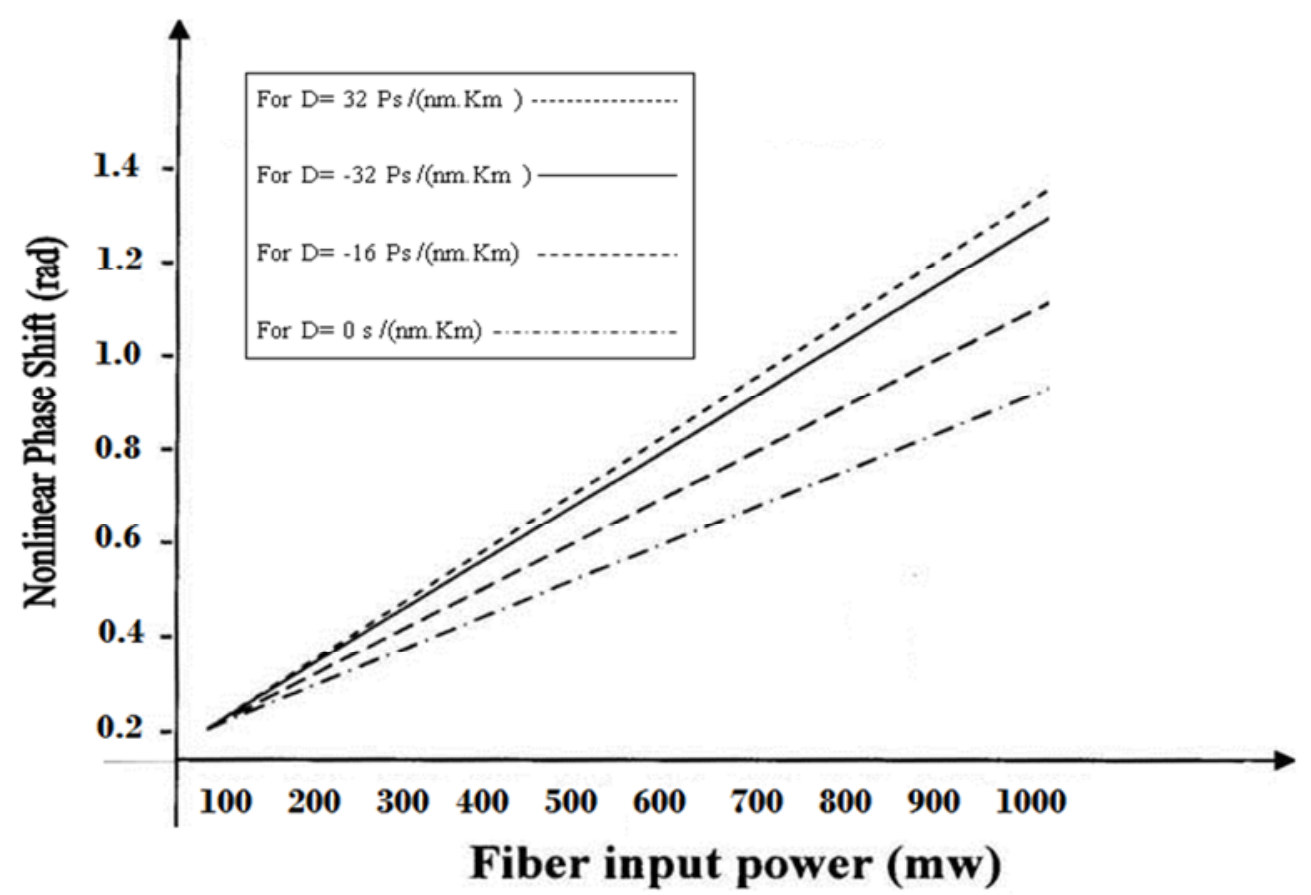

Fig. 2 Effect of fiber input power on nonlinearity. 


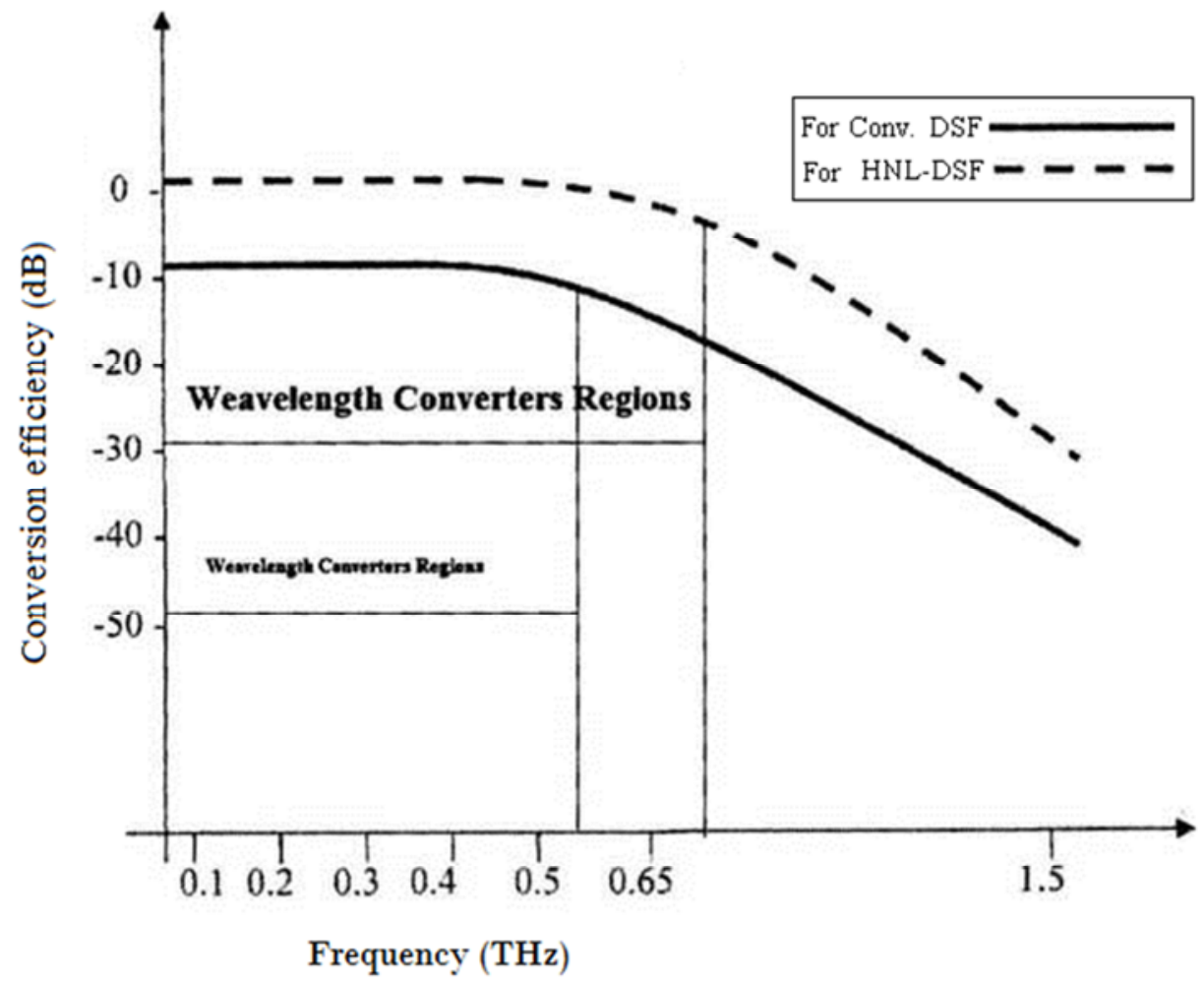

Fig. 3 Conversion efficiency vs. frequency.

\section{Conclusion}

The nonlinear coefficient can be determined from the slope of the nonlinear phase shift as a function of the optical input power. To take into account chromatic dispersion, one can solve the "SNDE" and add the effect of chromatic dispersion to the result obtained.

\section{References}

[1] G. P. Agward, "Nonlinear fiber optics", San Diego CA, Academic press, 2001.

[2] T. Okuno, M. Onishi, T. Kashiwada, S. Ishikawa and M.Nishimura, "Silica base function of fibers with enhanced nonlinearity and their application", IEEE. J. Sel. Topics Quantum Electronics "Vol. 5, No.5, pp. 1385-1391, Sept.-Oct. 1999.

[3] R. Stolen and J. Bjorkholm,"Parametric amplification area frequency conversion in optical fibers", IEEE Journal of Quantum Electronics, Vol. 18, PP. 1062-1072,1982.

[4] S. Wen., "Optical phase conjugation of multiwavelength signals in a dispersion shifted fibers", J. Lightwave Technology ,Vol. 15, No.7, 1061-1070, July 1997.

[5] M. Sauer, D. Nolan ,M. Li, and G. Berkey,"Simultaneous multichannel pulse compensation for broadband dynamic dispersion compensation", Optical Fiber Communication Conference, Atlanta ,Ga, March 23-28, 2003, Vol. 1, pp. 298-300.

[6] S. Li, M. Sauer, Z. D. Gaeta and D. A. Nolan, "Broadband dynamic dispersion compensation in nonlinear fiber-based device", J. Lightwave Technology, Vol. 22, No. 1, pp. 29-38, Jan. 2004.

[7] J. Lec, T. Nagash, Ma. S. Ohara, and K. Kikuchi, "Bismuth-oxide-based nonlinear fibers and its application to four-wave mixing and wave length conversion", J. Lightwave 
Technology., Vol. 24, Jan. 2006.

[8] X. Xio, P. Shum, S. Nazemo Sadat, and C. Yang, “Four-wave mixing of pulsed signal in dispersion-shifted fiber with pump depletion", IEEE Photonics Tech. Letters, Vol. 20, No. 14, July 2008.

[9] N. Shibata, R. Braun and R. G. Waarts, "Phase mismatch dependence of efficiency of wave generation through four-wave mixing in single mode optical fibers", IEEE Journal of Lightwave Technology, Vol. 17, No.11, pp. 2285-2290, 1999.

[10] A. Bogris and D. Syvridis, "Regenerative properties of a pump-modulated four-wave mixing scheme in dispersion-shifted fibers", Journal of Lightwave Technology, Vol. 21, No. 9, pp. 1892 - 1902, Sept. 2003 